$$
\text { دراسة امتزاز صبغة الأيوسين على سطح مخلفات دبس التمر }
$$

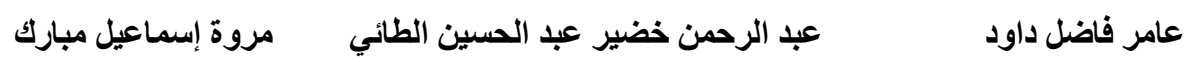

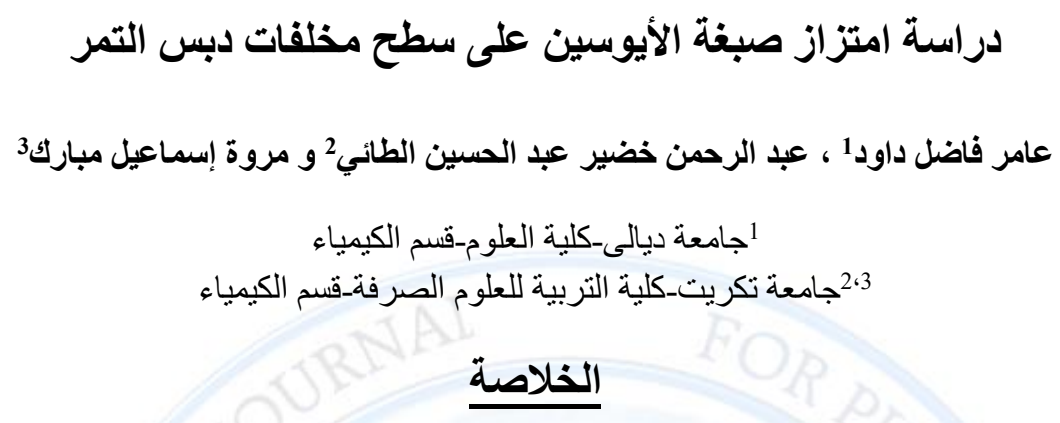

في هذا البحث تم إز الة صبغة الأيوسين من المحاليل المائية على سطح نباتي ( مخلفات دبس التمر ). تم تحديد زمن الاتزان

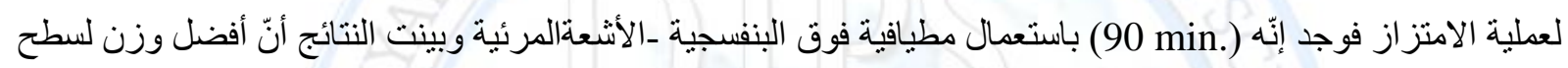

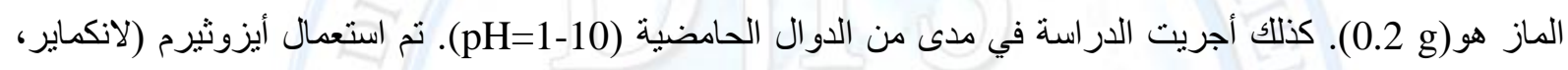

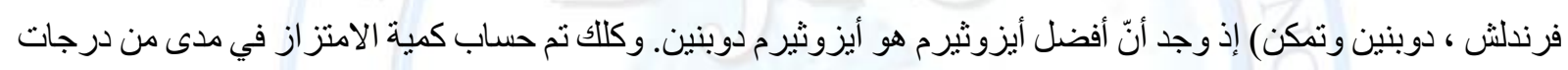

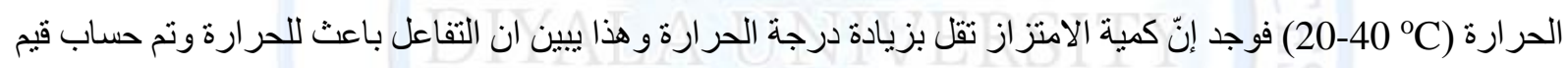
الدوال الثرموديناميكية لعملية الامتزاز وأجريت دراسة حركية للامنز از فوجد ان الامتز از يتبع معادلة المرتبة الثانية الكاذبة وحسبت ثو ابت السر ع و الدو ال الثرموديناميكية للتنشيط للتفاعلين الامامي و العكسي. كلمات مفتاحية: ـالامتزاز، أيزوثرمات، دراسة حركية، صبغة الايوسين، مخلفات دبس التمر.

\title{
Study Eosin Dye Adsorption on the Surface Waste of Molasses Dates Production
}

Amer Fadhil Dawood ${ }^{1}$, Abd AL-Rahman Khudheir AL- Taie ${ }^{2}$ and Marwa Ismail Mubarak $^{3}$

${ }^{1}$ Diyala University - College of Science - Chemistry Department 2 and 3 Tikrit University - College of Education for Pure Science - Chemistry Department

Received 4 May $2016 \quad$ Accepted 5 June 2016 


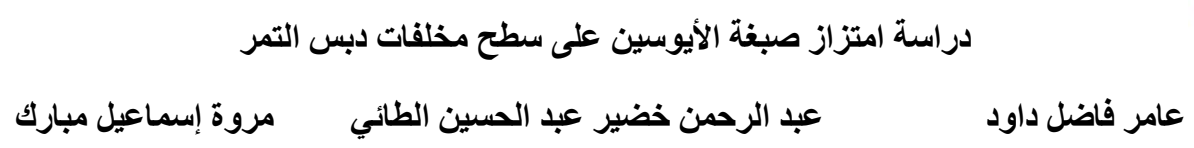

\section{$\underline{\text { Abstract }}$}

In this paper has been removed from the Eosin dye aqueous solutions on the surface Plant (waste of molasses dates production). It was determined to equilibrium time the process of adsorption and found that (90 min.) Spectroscopy using ultraviolet - visible rays and the results showed that the best weight for the surface of the adsorbent is $(0.2 \mathrm{~g})$. Moreover, the study was conducted in a range of acidic state $(\mathrm{pH}=1-10)$. Isotherm been used (for Langmuir, Freundlich, Dubinin, Temkin) as it was found that the best Isotherm is Isotherm Dubinin. And the amount of adsorption was calculated in the range of temperatures $\left(20-40{ }^{\circ} \mathrm{C}\right)$ and found that the amount of adsorption decreased with increasing temperature and this shows that the interaction exothermic was calculated valuable thermodynamic functions and was conducted kinetic study of the adsorption and found that the adsorption follows the equation second false constants were calculated velocities and thermodynamic functions activation of front and reverse reaction Keywords:-adsorption, Isotherms, Kinetic study, Eosin dye, Waste of molasses dates production

\section{المقدمة}

إنّ التلوث من مشاكل العصر الر اهن التي تتطلب معرفة كيفية التخلص منهاو هذه المشكلة تزداد خطورة بسبب الدور الواضح الذي يلعبه الانسان في تفاقهها (1). ومن أحد أنو اعه التلوث البيئي و الذي يشمل تلوث التربة بسبب المواد الكيميائية او نتيجة سقوط أمطار حامضية (2). إنّ تلوث المياه الجوفية ومياه الصرف الصحي يأتي أيضا من المؤسسات العامة و التجارية لنفايات الصناعية السائلة (3) و اللذين لهما أثار سيئة وسلبية على صحة الانسان (4). وتزداد مشكلة التلوث البيئي في البلدان النامية و المتطورة في الصناعات وخاصتا مشكلة تلوث مياه الصرف الصحي وحسب المنظمات الإنسانية والعالمية اعتبر ذلك مصدرَ قلقي ومن هذه الصناعات التي تزيد مشكلة تلوث مياه الصرف الصحي هي صناعات صبغ المنسوجات و الجلود ولوحظ أنّ ولن العديد من هذه الصبغات مسرطنة وسامة وتسبب تشو هات خلقية (5). توجد عدة طرق لمعالجة تلوث المياه منها التناضح

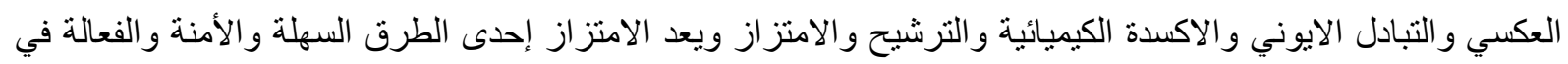
معالجة تلوث المياه. إنّ عملية إزالة الصبغة عن طريق الامتزاز باستخدام ماز بأقل تكلفة عملية ناجحة اقتصادياً ومن أمثلة المواد المازة هي وقتشور الأرز (6) وقثور الفاكهة ومخلفات دبس التمر والمطاط (7). و هنالك نوعين من الامتزاز كيميائي وفيزيائي و هناك عدة عوامل تؤثر على الامتزاز منها حجم الجزيئات الممتزة ومسامية السطح الماز ودرجة الحرارة وزمن الاتز ان و الدالة الحامضية. 
دراسة امتزاز صبغة الأيوسين على سطح مخلفات دبس التمر

عبد الرحمن خضير عبد الحسين الطائي مروة إسماعيل مبارك

عامر فاضل داود

\section{المواد والطرق}

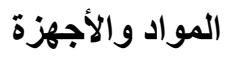

الصبغة التي استعملت في هذه الدر اسة هي صبغة الأيوسين وتسمى أيضا (eosin yellowish (eosin Y ws). إنّ المادة المازة (السطح) التي تم استعمالها في هذه الدراسة هي مخلفات دبس التمر اذ تم غسل مخلفات دبس التمر عدة مرات لإز الته الثو ائب ومن ثم تم تجفيفها في الفرن لمدة ساعتين وبدرجة حر ارة 120مئوية ومن ثم طحنت بشكل مسحوق بقطر 75 بm إمّا الأجهزة التي استخدمت فهي: -مطياف الاشعة المرئية_فوق البنفسية (UV-Visible) لتحليل ومعرفة تركيز المادة الممتزة عند التوازن وحمام مائي ذي هزاز ومسيطر على درجة حر ارته.

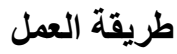
تم تعيين أيزوثرمات الامنز از لصبغة الأيوسين من خلال تحضير عشرة تر اكيز من (20 ppm) من التركيز الأصلي

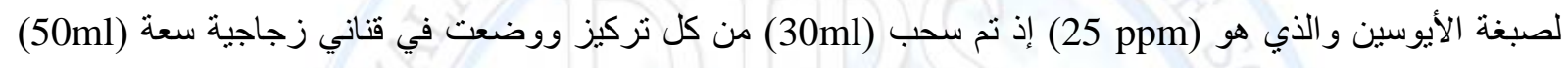
وبتماس مع الوزن المحدد للسطح الماز والذي هو (0.2 0 لمخلفات دبس التمر وتم تغطيتها جيدا ووضعت في حمام مائي مزود بهزاز بسرعة (rpm 185 ) ومسيطر على درجة الحرارة عند 25 مئوية وبعد الوصول الى زمن الاتزان المحدد ينم ترشيحها وتوضع في انبوبة اختبار بلاستيكية وتوضع في جهاز الطرد المركزي لمدة (15 min) وبقوة (3500 rpm) ومن ثم تم ترشيحها مرة أخرى وقيست لها الامتصاصية ونم حساب كمية المادة المنزة ( (Qe mglg) بحسب العلاقة التالية (8):$Q_{e}=\frac{C_{o}-C_{e}}{m} . V_{s o l}$

وتم دراسة حركية الامتزاز لصبغة الأيوسين على سطح مخلفات دبس التمر من خلال تحضير 12 قنينة زجاجية سعة (50ml) ويوضع في كل قنينة (30ml) من صبغة الأيوسين ذو تركيز(10ppm) و(0.2g) من مخلفات دبس التمر ويتم

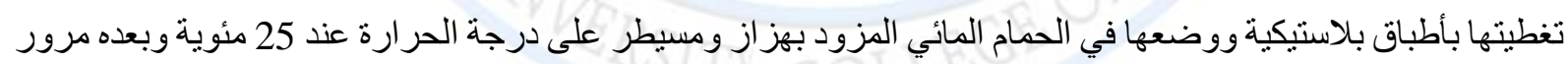
خمسة دقائق تسحب القنينة الأولى ويتم ترشيحها بأوراق الترشيح وتوضع في جهاز الطرد المركزي لمدة (15 (15) وبسر عة (3500 rpm) ومن ثم يتم ترشيحها مرة أخرى وتقاس لها الامتصاصية عند الطول الوجي المثبت بجهاز المطيافية الأشعة المرئية ـ فوق البنفسجية و بعده مرور عشرة دقائق تسحب القنينة الثانية وتعاد نفس الخطوات التي اتبعت مع القنينة

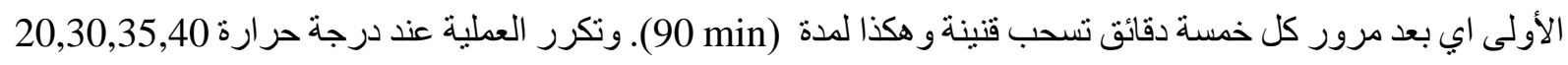

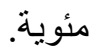


دراسة امتزاز صبغة الأيوسين على سطح مخلفات دبس التمر

عبد الرحمن خضير عبد الحسين الطائي مروة إسماعيل مبارك

عامر فاضل داود

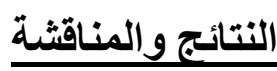

تحديد زمن الاتزان

هذه الخطوة مهمة من البحث بإجر اء در اسة حركية تهدف إلى متابعة تغير امتز از لصبغة قيد الدراسة مع الزمن وتحديد الزمن اللازم لوصول نظام الامتزاز الى التوازن وتمت الدر اسة بتركيز ثابت من صبغة الأيو سين (10ppm) ودالة حامضية ثابتة وكمية ثابتة من السطح الماز (g 0.2). إذ أوضحت الدر اسة أنّ عملية الوصول إلى حالة الاتز ان في زمن (90 دقيقة) لمخلفات دبس التمر و النتائج موضحة في شكل (1) لمخلفات دبس التمر.

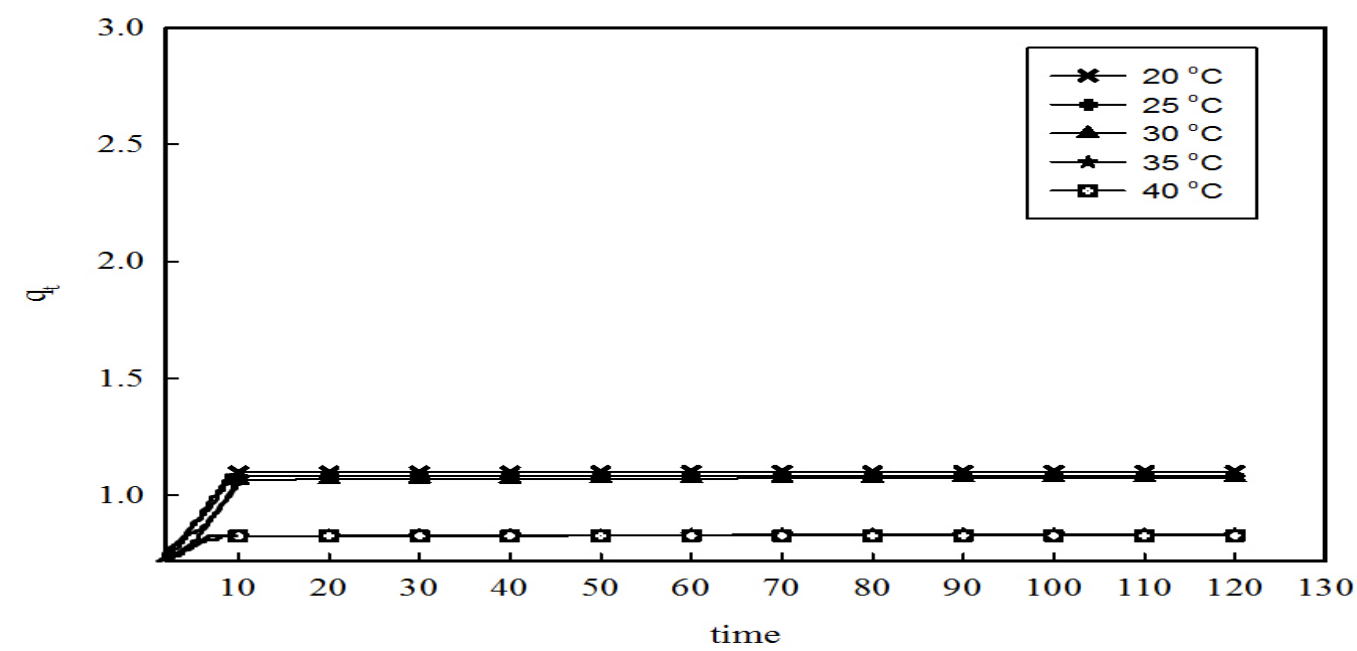

شكل(1) زمن الاتزان لامتزاز صبغة الائوسين على سطح مخلفات دبس التمر وبدرجات حرارية مختلفة.

من خلال النتائج الموضحة أعلاه يتبين ان كمية المادة الممتزة بعد مرور 10دقائق تز اد وتستمر هذه الزيادة إلى زمن معين ثم

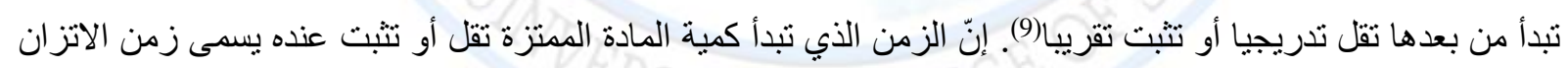

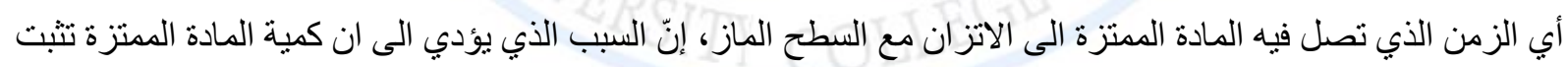

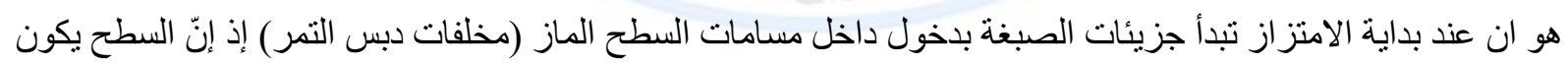

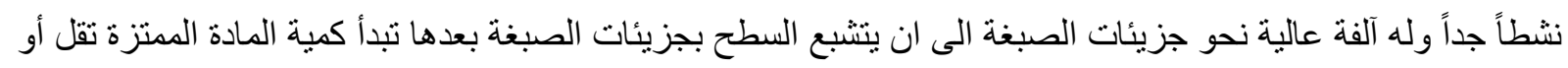
تثبت تدريجيا بسبب مقاومة انتشار هذه الجزيئات وبذلك يمكن الاستنتاج ان انتشار جزيئات الصبغة داخل مسامات السطح هي الخطوة المسيطرة على الامتزاز.

تأثير وزن السطح الماز إنّ تأثير وزن سطح الماز على امتزاز صبغة الأيوسين تم دراسته من خلال تغير وزن السطح الماز (مخلفات دبس التمر) ضمن مدى ( 0.05-0.5g) مع بقاء تركيز الأصلي لصبغة الأيوسين ثابت وهو (10ppm) والدالة الحامضية ثابتة والحر ارة 
دراسة امتزاز صبغة الأيوسين على سطح مخلفات دبس التمر

عبد الرحمن خضير عبد الحسين الطائي مروة إسماعيل مبارك

عامر فاضل داود

ثابتة عند (25 C) وزمن ثابت (90 min) لسطح مخلفات دبس التمر . إذ إنّ النتائج موضحة شكل (2). ويمكن حساب نسبة

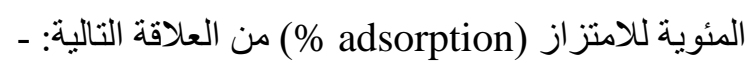

\%adsorption $=\frac{C_{o}-C_{e}}{C_{o}} \times 100$

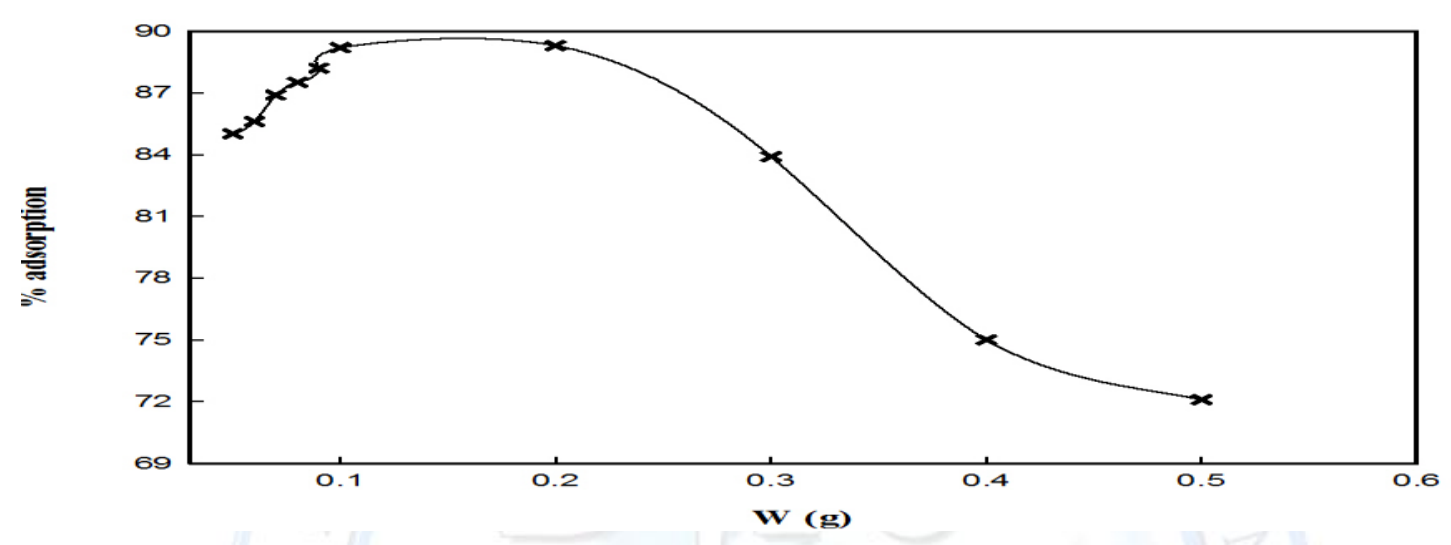

شكل (2) وزن السطح الماز ونسبة المئوية للامتزاز لصبغة الأيوسين على سطح مخلفات دبس التمر.

إنّ نسبة المئوية للامتز از نجد أنّها تزداد مع زيادة وزن السطح وصو لا إلى وزن (0.2g) نجد عنده اقصى نسبة بعد هذا

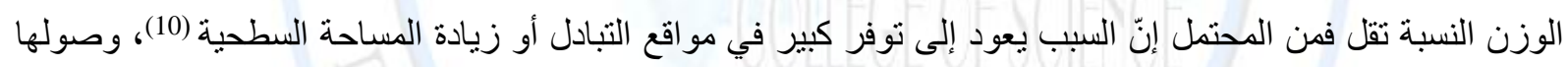
للتشبع.

تأثير الدالة الحامضية

إنّ تأثير الدالة الحامضية على امنز از صبغة الأيوسين على السطح مخلفات دبس التمر نم دراسته بتغير الدالة الحامضية ضمن مدى (10-7-4) وبتر اكيز مختلفة من صبغة الأيوسين ضمن مدى (2-20ppm) مع الحفاظ على درجة الحر ارة ثابتة

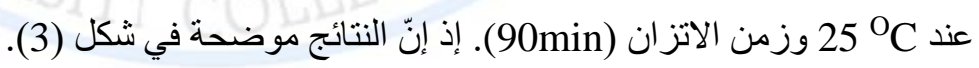

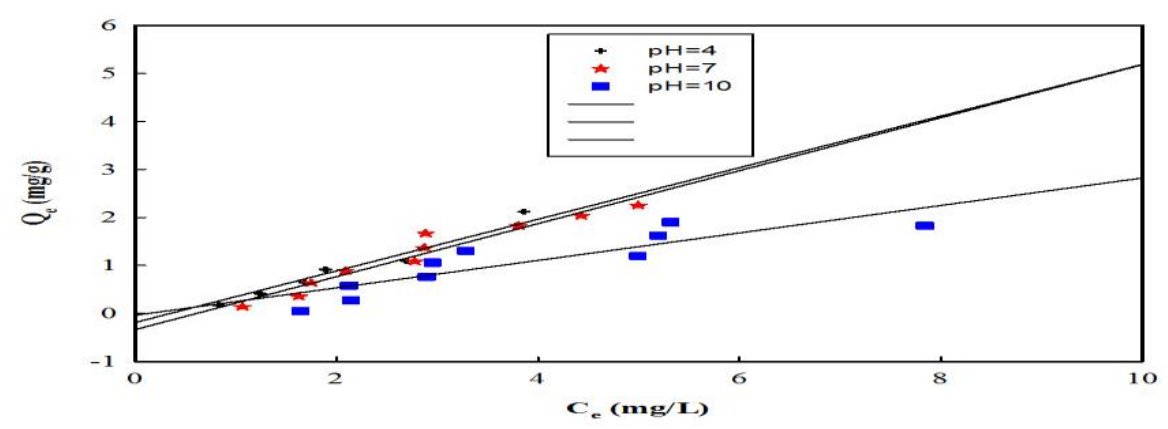

شكل (3) تأثير الدالة الحامضية على امتزاز صبغة الأيوسين على سطح مخلفات دبس التمر عند درجة حرارة C C 25. 
دراسة امتزاز صبغة الأيوسين على سطح مخلفات دبس التمر

عبد الرحمن خضير عبد الحسين الطائي مروة إسماعيل مبارك

عامر فاضل داود

إنّ الدالة الحامضية تؤثر على السطح الماز و المادة الممتزة و على التداخلات التي تحدث بينهما. في الدراسة تم التوصل إلى ان النسبة المئوية للامنز از على سطح مخلفات دبس التمر تقل مع زيادة الدالة الحامضية ان السطح يحتوي على مجاميع (pH=4) تزداد الثحنة الموجبة على السطح نتيجة كثرة البروتونات، ومن ناحية أخرى فان زيادة تركيز ايونات الهيدروجين يعمل على إز احة ( (Na) من مجاميع (-ONa -CO -CO2) في صبغة الأيو سين ويحل محلها من غير ان يغير في اللون أو الطول الموجي الأعظم لذلك نسبة التداخل تزداد بين الصبغة و السطح من خلال الارتباط بين ذرات الاوكسجين لصبغة الأيوسين و السطح. بالتالي يزداد ميل الصبغة للارتباط بسطح أكثر من ميلها للارتباط بجزيئات المذيب. لذلك تزداد كمية المادة الممتزة في الوسط الحامضي. إمّا في الوسط القاعدي ذو(pH=10) فتقل النسبة المئوية

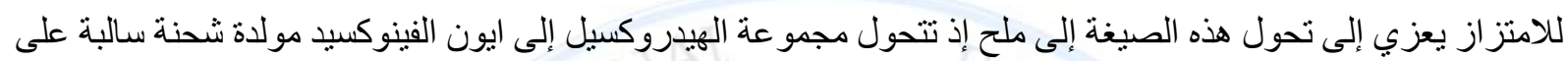

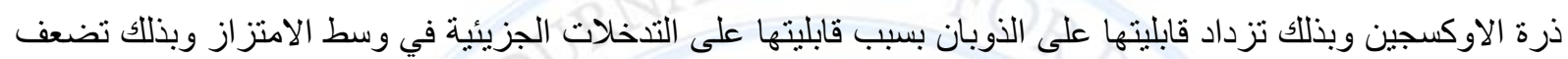
من نسبة الامتز ازوان السطح سوف يكتسب شحنة سالبة من خلال المحلول. و إنّ مجمو عات الهيدروكسيل تعمل على سحب لابل من صبغة الايوسين من مجموعة (Na+) اللون او الطول الموجي الأعظم. بالتالي سوف يحدث تنافر شديد للثحنات المتماثلة للصبغة والسطحين فتقل كمية المادة الممتزة على السطح لحدوث تنافر الالكتروستاتيكي بينهما. إمّا عند در اسة أفضل دالة حامضية لسطح فوجدت عند (pH=1)

حيث كلما يكون الوسط حامضي تزداد نسبة المئوية للامتز از على السطح ونتائج موضحة في شكل (4).

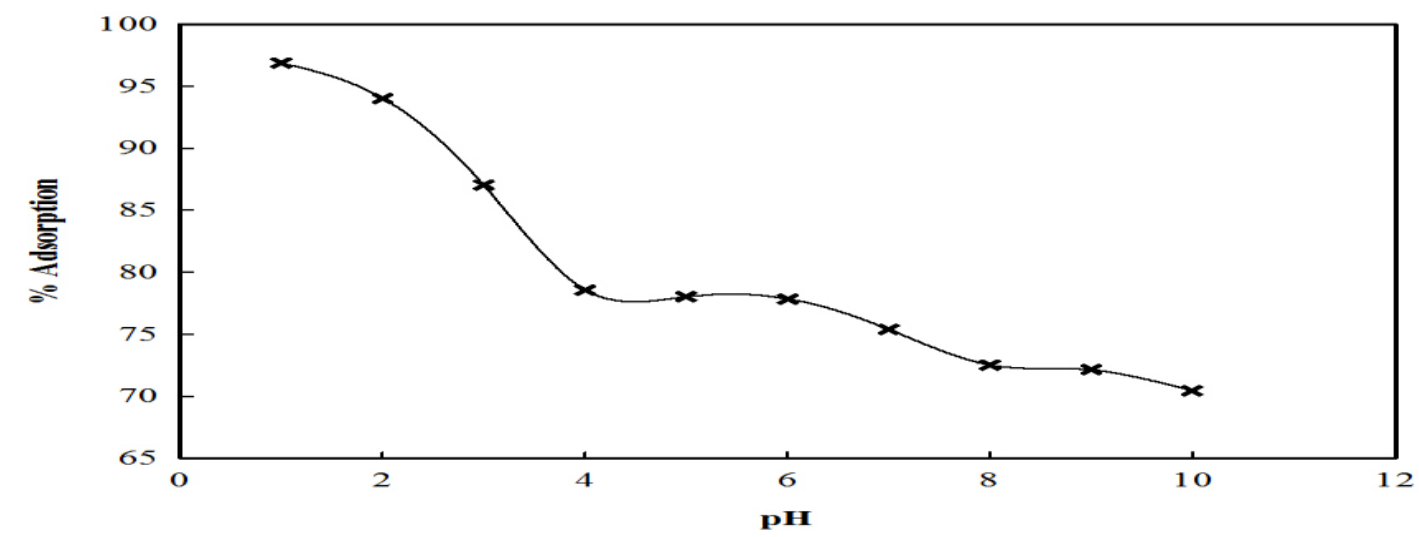

شكل (4) تأثير تغير الدالة الحامضية على النسبة المئوية لامتزاز صبغة الأيوسين على سطح مخلفات دبس التمر.

تأثير درجة الحرارة على الامتزاز تم در اسة تأثير درجة الحرارة على امتز از صبغة الأيو سين في مدى (20-40 C موضحة في شكل (5). النتائج تشير إلى إنّ كمية الامتزاز لصبغة الأيوسين تقل مع زيادة درجة الحر ارة. إذ يمكن تفسير هذا

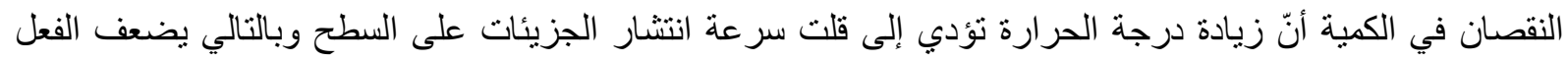


دراسة امتزاز صبغة الأيوسين على سطح مخلفات دبس التمر

عبد الرحمن خضير عبد الحسين الطائي مروة إسماعيل مبارك

عامر فاضل داود

المنبادل بين السطح الماز وجزيئات المادة الممتزة وسوف تتفصل الروابط بينهما(11). وينطابق هذا الكلام مع الدوال

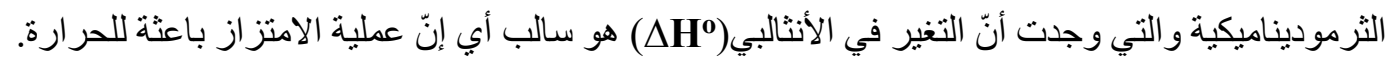

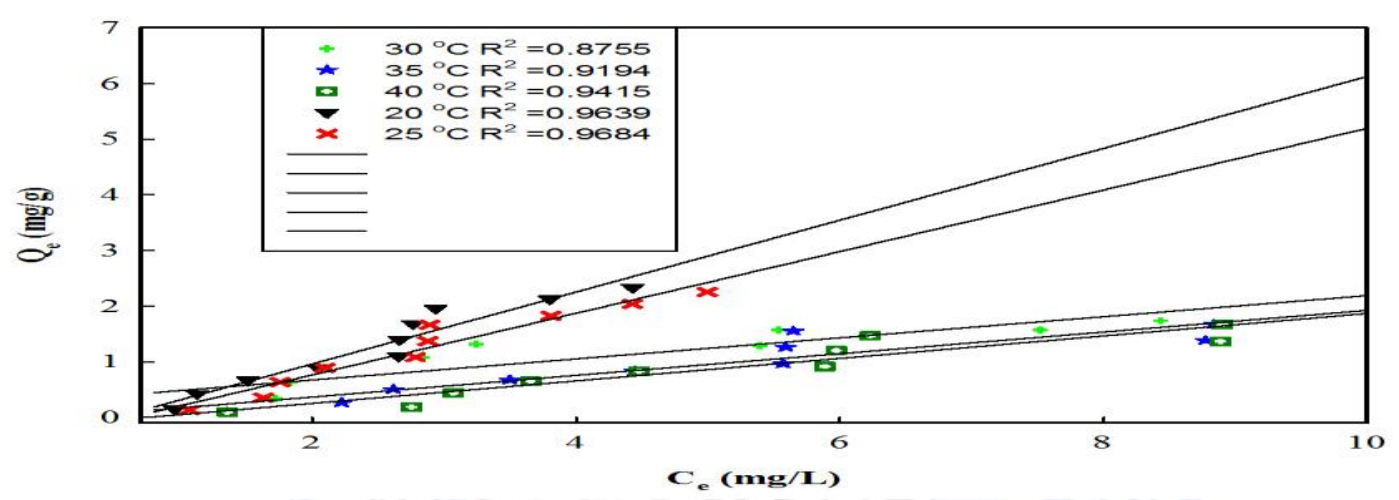

شكل (5) تأثير تغير درجة الحرارة على امتزاز صبغة الأيوسين على سطح مخلفات دبس التمر.

حساب الدوال الثرموديناميكية

تعد قيم الدو ال الثرموديناميكية مهمة جدا في تفسير الكثير من التفاعلات (و لاسيما عملية الامتزاز) من حيث اتجاه سير ها وطبيعة القوى المسيطرة عليها فضلا عن أنّها تعطي وصفا جيدا عن طبيعة انتظام الجزيئات في الانظمة المختلفة الناتجة عن

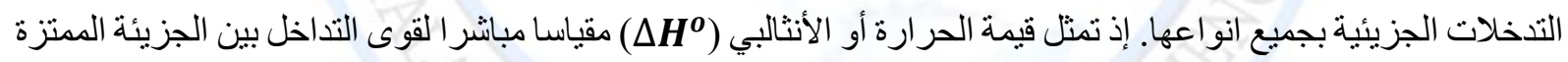
و السطح الماز وتم حساب قيمة الأنثالبي باستخدام معادلة فونت هوف و التي هي: -

$K_{C}=\mathbf{A e}^{-\Delta H^{o} / R T}$

$\ln \mathrm{X}_{\mathrm{m}}=-\frac{\Delta H^{o}}{\mathrm{RT}}+\mathrm{k}$

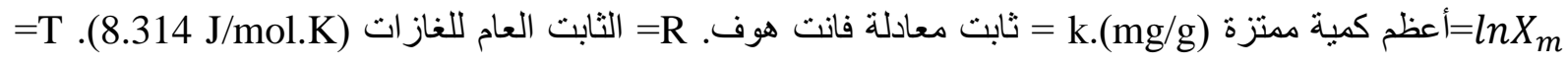
درجة الحرارة بالكلفن. من خلال رسم العلاقة بينm إln ومقلوب درجة الحرارة(1/T) نحصل من الميل على( في شكل (6). ونتائج الدوال الثرموديناميكية موضحة في جدول (1). ويمكن الحصول على التغير في الطاقة الحرة (التي يتم التعرف من خلالها على تلقائية أو عدم تلقائية التفاعل من العلاقة التالية: - 
دراسة امتزاز صبغة الأيوسين على سطح مخلفات دبس التمر

عبد الرحمن خضير عبد الحسين الطائي مروة إسماعيل مبارك

عامر فاضل داود

$\Delta G^{o}=-\mathrm{RT} \ln \mathrm{K}$

إذ تبين أنّ امتزاز صبغة الأيوسين على سطح تكون تلقائية ومن خلال علاقة جبس يمكن تحديد التغير في الانتروبي (AS

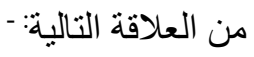

$\Delta G^{o}=\Delta H^{o}-\mathrm{T} \Delta S^{o}$

$\Delta S^{o}=\frac{\Delta H^{o}-\Delta G^{o}}{\mathrm{~T}}$

إذ إنّ تغير في الانتروبي لصبغة الأيوسين على سطح مخلفات دبس التمر يكون سالب هذا يدل على أنّ جزيئات الممتزة صبغة الايوسين تنتظم على السطح أكثر من محلول.

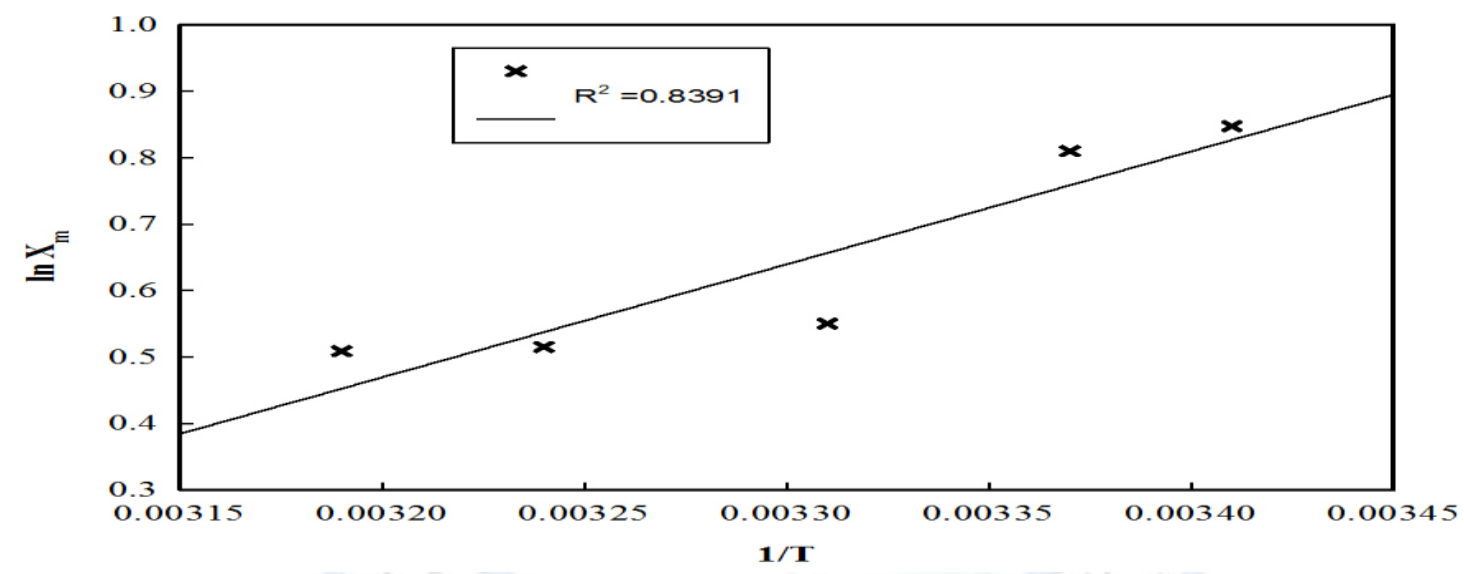

شكل(6) كميات الامتزاز العظمى (ln X مخلفات دبس التمر.

جدول (1) قيم الدوال الثرموديناميكية لصبغة الأيوسين على سطح مخلفات دبس التمر وبخمس درجات حرارية .(20,25,30,35,40 $\left.{ }^{\circ} \mathrm{C}\right)$

\begin{tabular}{|c|c|c|c|c|c|c|}
\hline $\begin{array}{c}\mathrm{C}_{\mathrm{e}} \\
(\mathrm{mg} / \mathrm{L})\end{array}$ & $\begin{array}{c}\text { Thermodynamic } \\
\text { parameters }\end{array}$ & $20^{\circ} \mathrm{C}$ & $25^{\circ} \mathrm{C}$ & ${ }^{\circ} \mathrm{C} 30$ & ${ }^{\circ} \mathrm{C} 35$ & $40^{\circ} \mathrm{C}$ \\
\hline \multirow{3}{*}{ 20ppm } & $\begin{array}{c}\Delta H^{o} \\
\text { kJ.mol } \\
\end{array}$ & \multicolumn{5}{|c|}{-14.143} \\
\hline & $\begin{array}{c}\Delta G^{o} \\
\text { kJ.mol }\end{array}$ & -3.062 & -2.724 & -0.793 & -0.597 & -0.572 \\
\hline & $\begin{array}{c}\Delta S^{o} \\
\text { J.mol } \\
-\mathbf{H}^{-1} \mathbf{K}^{-1}\end{array}$ & $0.0378-$ & $0.0383-$ & $0.0440-$ & 0.0439- & $0.0433-$ \\
\hline
\end{tabular}


دراسة امتزاز صبغة الأيوسين على سطح مخلفات دبس التمر

عبد الرحمن خضير عبد الحسين الطائي مروة إسماعيل مبارك

عامر فاضل داود

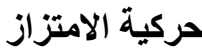

أُجريت الدر اسة الحركية على امتزاز صبغة الأيوسين باستخدام طريقة الوجبة (Batch method) و عند تركيز ( 10ppm) وفي مدى من الدرجات الحرارية (293-313K) مطلقة ونم تطبيق معادلة الآتي:-

$\ln (a-x)=\ln a-k_{1} t$

$\ln \left(C_{o-} q_{t}\right)=\ln C_{o}-k_{1} t$

نحصل من الميل على ثابت سر عة للتفاعل الأمامي (K/) من التقاطع على (lnq ) وتمثل هذه المعادلة المرحلة الابتدائية للتفاعل الامامي إذ ان الحركية تمر بمرحلتين. وجد ان قيم معامل الارتباط (correlation coefficient) (R2) هي (

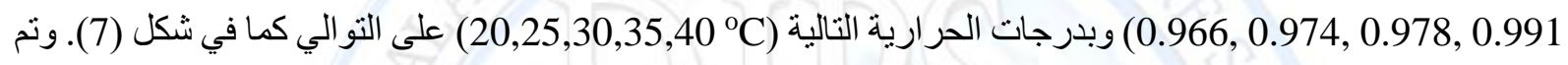
تحليل النتائج امتز از صبغة الأيوسين وفق معادلات المرتبة الأولى الكاذبة لأرجركرين للتفاعل العكسي وهي تمثل مرحلة

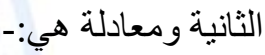

$\ln \left(q_{e}-q_{t}\right)=\ln q_{e}-\left(K_{1}+K_{-1}\right) t$

من خلال الرسم بين (ln (qe-qt ) و الزمن من ميل نحصل على ثابت السر عة التفاعل الأمامي و ثابت السرعة التفاعل

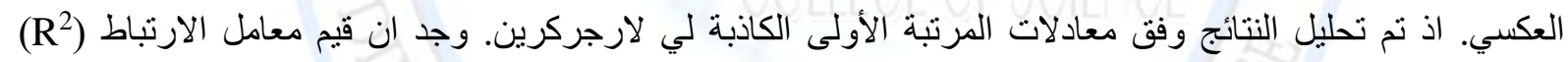
(0.854, 0.984, 0.667, 0.825, 0.679) هبدرجات الحرارية التالية (correlation coefficient) (20,25,30,35,40 على التو الي كما في الثكل (8) (8) و تم تحليل النتائج وفق معادلة المرتبة الثنانية الكاذبة(12) وهي: -

$\frac{\mathrm{t}}{\mathrm{q}_{\mathrm{t}}}=\frac{1}{\mathrm{~K}_{2} \mathrm{q}_{\mathrm{e}}^{2}}+\frac{1}{\mathrm{q}_{\mathrm{e}}} \mathrm{t}$

$\mathrm{h}=\mathrm{K}_{2} \mathrm{q}^{2}$

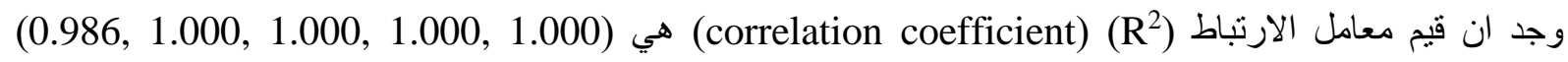
وبدرجات الحرارية التالية (20, 25, 30, 35, 40 C) على التو الي كما في الثكل (9). من قيم معامل الارتباط يتبين أنّ هذه

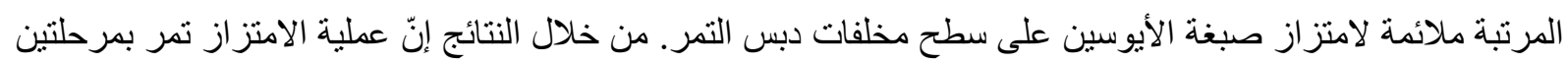

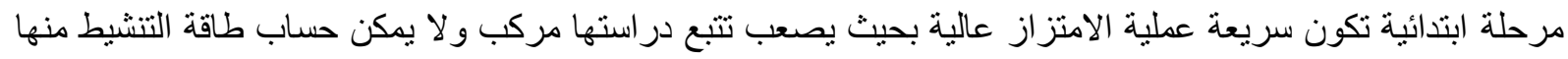
ويتبعها مرحلة بطيئة بعدها يصل النظام الامتزاز الى حالة التوازن و على غر ار التفاعلات المعاكسة وبالاستفادة من وصول الامتزاز الى حالة الاتزان نستخدم نموذج لارجركرين. و عند دراسة عملية الامتز از في درجات حرارية مختلفة وباستخدام

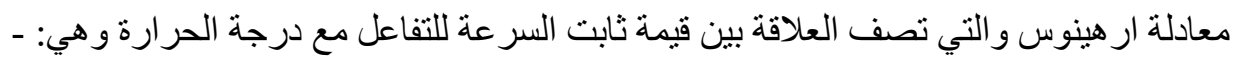


دراسة امتزاز صبغة الأيوسين على سطح مخلفات دبس التمر

عامر فاضل داود عبد الرحمن خضير عبد الحسين الطائي مروة إسماعيل مبارك

$\ln K=\ln A-\frac{E}{R T}$

و التي من خلال رسم العلاقة بين (ln k1) مقابل مقلوب درجة الحرارة بكلفن نحصل من الميل على قيمة طاقة التنشيط للتفاعل الأمامي ومن رسم العلاقة بين (ln k-1) مقابل مقلوب درجة الحر ارة بكلفن نحصل من ميل على قيمة طاقة التنشيط للتفاعل العكسي. وكذلك إنّ ثابت الاتزان يساوي حاصل قسمة ثابت السرعة التفاعل الأمامي على ثابت السرعة التفاعل العكسي كما في شكل (10) و شكل (11).إنّ متغير ات المرتبة الأولى الكاذبة و الثانية الكاذبة مدرجة في جدول (2). ويمكن حساب الدو ال الثرموديناميكية لتنشيط لكلا الاتجاهين باستخدام المعادلات الآتية: ـ

$\Delta \boldsymbol{H}^{*}=\boldsymbol{E}-\boldsymbol{R} \boldsymbol{T}$

فيما بمكن حساب قيمة (

$\mathbf{A}=\frac{K T}{h} \mathbf{e}^{\left(1+\frac{\Delta S^{*}}{R}\right)}$

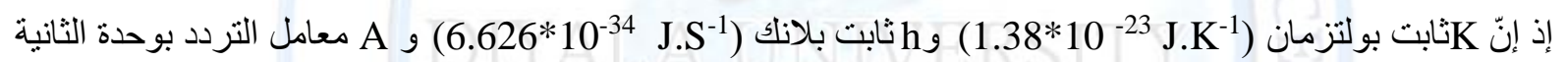
ويؤخذ ln لمعادلة الاخيرة مع اعادة الترتيب فتصبح كالاتي:-

$\Delta S^{*}=R\left[\ln A \cdot \ln \left[\frac{K T}{h}\right]-1\right]$ 
دراسة امتزاز صبغة الأيوسين على سطح مخلفات دبس التمر

عبد الرحمن خضير عبد الحسين الطائي مروة إسماعيل مبارك

عامر فاضل داود

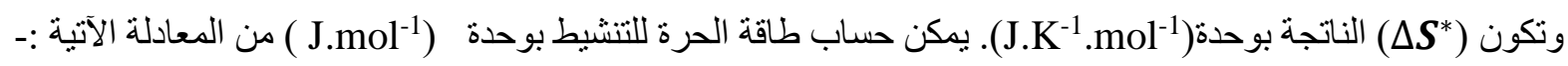

$\Delta \boldsymbol{G}^{*}=\Delta \boldsymbol{H}^{*}-\boldsymbol{T} \Delta \boldsymbol{S}^{*}$

كذللك تثير القيم الموجبة ( الامتزاز ويمكن حساب قيمة أنثالبي الامتزاز من الفرق بين أنثالبي الامتزاز للتنشيط في الاتجاه الأمامي و العكسي (ومن الملاحظ أيضا ان قيم ثابت السرعة التفاعل بالاتجاهين تزداد مع زيادة درجة الحرارة).و إنذ قيمها مدرجة في جدول (3).

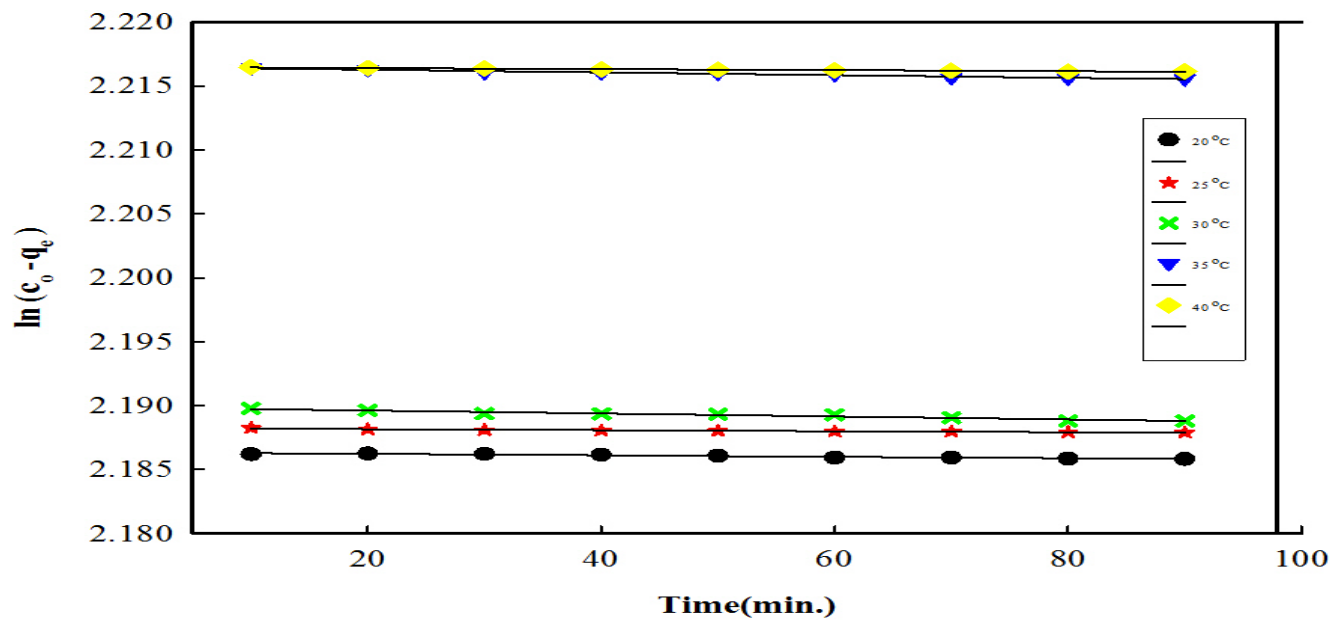

شكل (7) معادلة المرحلة الابتائية لامتزاز صبغة الأيوسين على سطح مخلفات دبس التمر وبخمس درجات حرارية

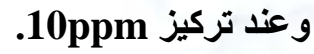

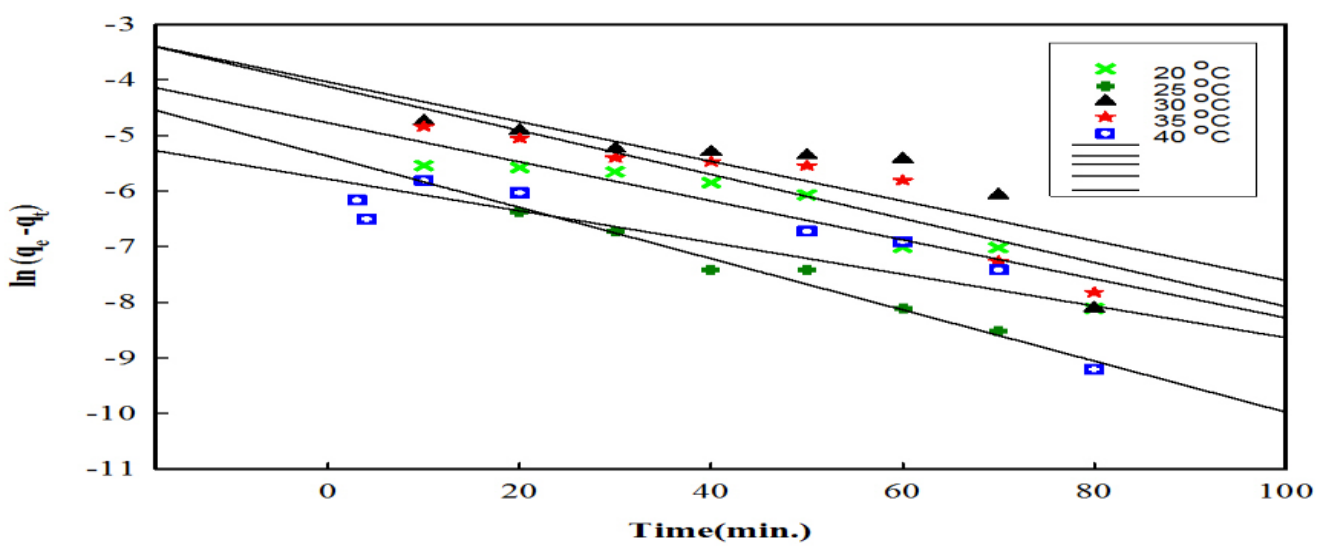

شكل (8) المرتبة الأولى الكاذبة لامتزاز صبغة الأيوسين على سطح مخلفات دبس التمر وبخمس درجات حرارية وعند تركيز 10ppm 


\section{DIYALA JOURNAL FOR PURE SCIENCES}

دراسة امتزاز صبغة الأيوسين على سطح مخلفات دبس التمر

عامر فاضل داود عبد الرحمن خضير عبد الحسين الطائي مروة إسماعيل مبارك

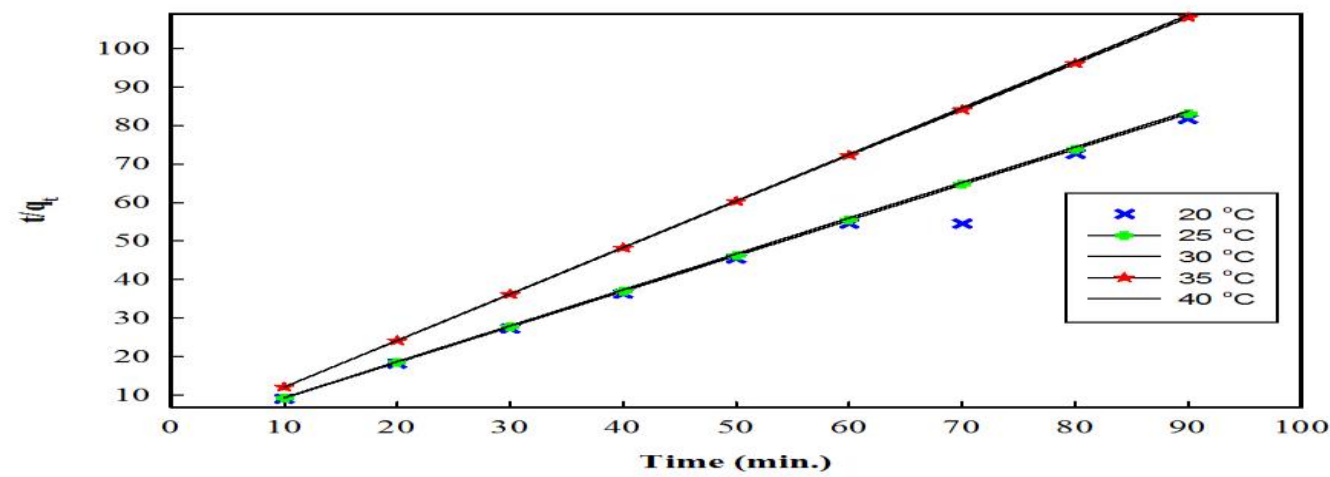

شكل (9) المرتبة الثانية الكاذبة لامتزاز صبغة الأيوسين على سطح مخلفات دبس التمر وبخمس درجات حرارية وعند

تركيز 10ppm

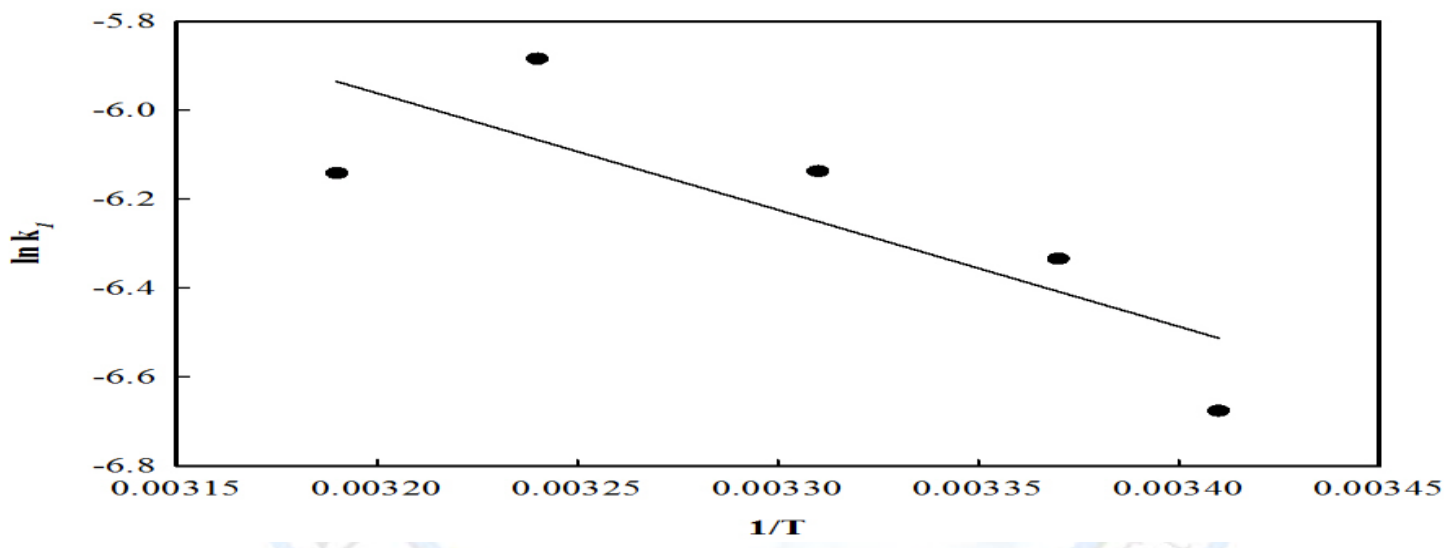

شكل (10) معادلة أرهينوس لتفاعل بالاتجاه الأمامي لامتزاز صبغة الأيوسين على سطح مخلفات دبس التمر.

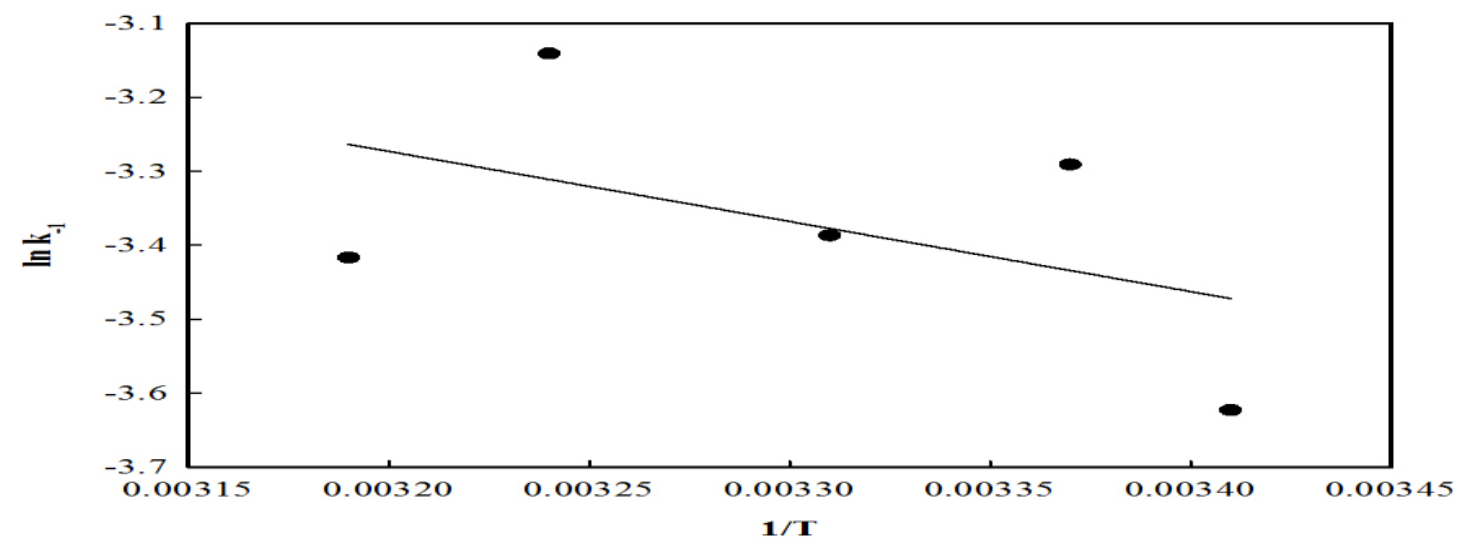

شكل (11) معادلة أرهينوس لتفاعل بالاتجاه العكسي لامتزاز صبغة الأيوسين على سطح مخلفات دبس التمر. 
دراسة (متزاز صبغة الأيوسين على سطح مخلفات دبس التمر

عبد الرحمن خضير عبد الحسين الطائي مروة إسماعيل مبارك

عامر فاضل داود

جدول (2) متغيرات مرتبة الأولى الكاذبة والثانية الكاذبة لامتزاز صبغة الأيوسين على سطح مخلفات دبس التمر وبخمس

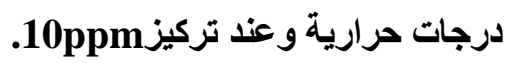

\begin{tabular}{|c|c|c|c|c|c|c|c|c|c|}
\hline \multirow{7}{*}{$\begin{array}{c}\mathrm{C}_{\mathrm{o}} \\
\text { 10pp } \\
\text { m }\end{array}$} & \multirow[b]{2}{*}{$\mathbf{T}\left(\mathbf{c}^{0}\right)$} & \multirow{2}{*}{$\begin{array}{c}\mathbf{q e} \\
\text { (exp.) }\end{array}$} & \multicolumn{3}{|c|}{ pseudo-first -order } & \multicolumn{4}{|c|}{ pseudo-second -order } \\
\hline & & & $\begin{array}{c}\mathbf{q e}_{\mathrm{e}} \\
\text { (calc.) }\end{array}$ & $\begin{array}{c}\mathbf{K}_{1} \\
\text { min }^{-1}\end{array}$ & $\mathbf{R}^{2}$ & $\begin{array}{c}\mathbf{q e} \\
\text { (calc.) }\end{array}$ & $\begin{array}{c}\mathrm{K}_{2} \\
\text { g.mg' } \\
\text { min }^{-1}\end{array}$ & H & $\mathbf{R}^{2}$ \\
\hline & 20 & 1.101 & 8.899 & 5.800 & 0.854 & 1.140 & 1.303 & 1.696 & 0.985 \\
\hline & 25 & 1.083 & 8.917 & 3.966 & 0.984 & 1.083 & 17.75 & 20.820 & 1.000 \\
\hline & 30 & 1.075 & 8.926 & 1.166 & 0.667 & 1.076 & 5.076 & 5.878 & 1.000 \\
\hline & 35 & 0.833 & 9.170 & 1.056 & 0.825 & 0.834 & 5.809 & 4.043 & 1.000 \\
\hline & 40 & 0.828 & 9.171 & 4.100 & 0.679 & 0.828 & 15.666 & 10.903 & 1.000 \\
\hline
\end{tabular}

جدول (3) ثوابت السرع بالاتجاه الأمامي والعكسي ودوال الثرموديناميكية للمعقد المنشط لامتزاز صبغة الأيوسين على سطح مخلفات دبس التمر.

\begin{tabular}{|c|c|c|c|c|c|c|c|c|}
\hline & \multicolumn{4}{|c|}{ التفاعل بالاتجاه الامامي } & \multicolumn{4}{|c|}{ التفاعل بالاتجاه العكسي } \\
\hline$T\left(c^{0}\right)$ & $\overline{\mathbf{K}_{1}}$ & $\Delta \boldsymbol{H}^{*}$ & $\Delta \boldsymbol{S}^{*}$ & $\Delta \boldsymbol{G}^{*}$ & K-1 & $\Delta \boldsymbol{H}^{*}$ & $\Delta \boldsymbol{S}^{*}$ & $\Delta \boldsymbol{G}^{*}$ \\
\hline 20 & -6.676 & -2308.336 & -216.187 & 61034.513 & -3.623 & -2154.921 & -238.451 & 68442.11 \\
\hline 25 & -6.334 & -2349.906 & -216.323 & 62114.526 & -3.291 & -2196.491 & -238.592 & 68904.103 \\
\hline 30 & -6.137 & -2391.476 & -216.466 & 63197.903 & $\begin{array}{l}3.387 \\
\end{array}$ & -2238.061 & -238.730 & 70097.310 \\
\hline 35 & -5.884 & -2433.046 & -216.602 & 64280.646 & -3.141 & -2279.631 & -238.867 & 71291.404 \\
\hline 40 & -6.141 & -2474.616 & -216.736 & 65364.180 & -3.417 & -2321.202 & -239.001 & 72486.048 \\
\hline $\mathrm{E}^{*}$ & & 127 & & & & 28 & & \\
\hline
\end{tabular}

أيزوثرمات الامتزاز

إنّ معلومات التي تعطيها أيزوثرمات الامتزاز مهمة. إذ أنّها تعطي فكرة عن كيفية توزيع الجزيئات بين الطور السائل و الطور

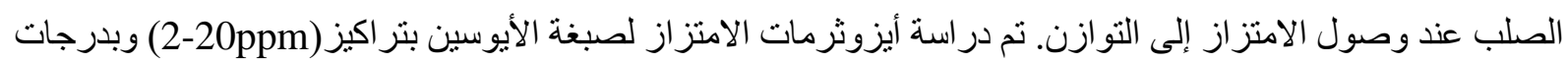
حر ارية (20,25,30,35,40 ) ونتائج موضحة في شكل (5). إنّ كل أيزوثرمات الامتز از لصبغة الأيوسين تثشير إلى أنّها من نوع S بحسب تصنيف Giles. الأيزوثيرم من نوع S يعتمد على افتر اضيات أيزوثيرم فرندلخ، والتي تتضمن أنّ السطح الماز يكون غير متجانس. و هذه الخاصية عامة والسبب يعود إلى اختلاف مو اقع الامتزاز الغير مشبعة واختلاف الطاقة. إنّ لان نتائج الامتزاز حللت وفق أيزوثيرم لانكماير الخطية كما في شكل (12) و التي هي: $\frac{\mathrm{C}_{\mathrm{e}}}{\mathrm{Q}_{\mathrm{e}}}=\frac{1}{\mathrm{~K}_{\mathrm{l}} \mathrm{q}_{\max }}+\frac{1}{\mathrm{q}_{\max }}$ 
دراسة امتزاز صبغة الأيوسين على سطح مخلفات دبس التمر

عبد الرحمن خضير عبد الحسين الطائي مروة إسماعيل مبارك

عامر فاضل داود

إنّ قيم معامل الارتباط (R2) و التي تكون بين مدى (0.420-034) نلاحظ أنّها قلليلة مما يدل على عدم ملائمة هذه المعادلة لنتائج امتزاز صبغة الأيو سين على السطح مخلفات دبس التمر.

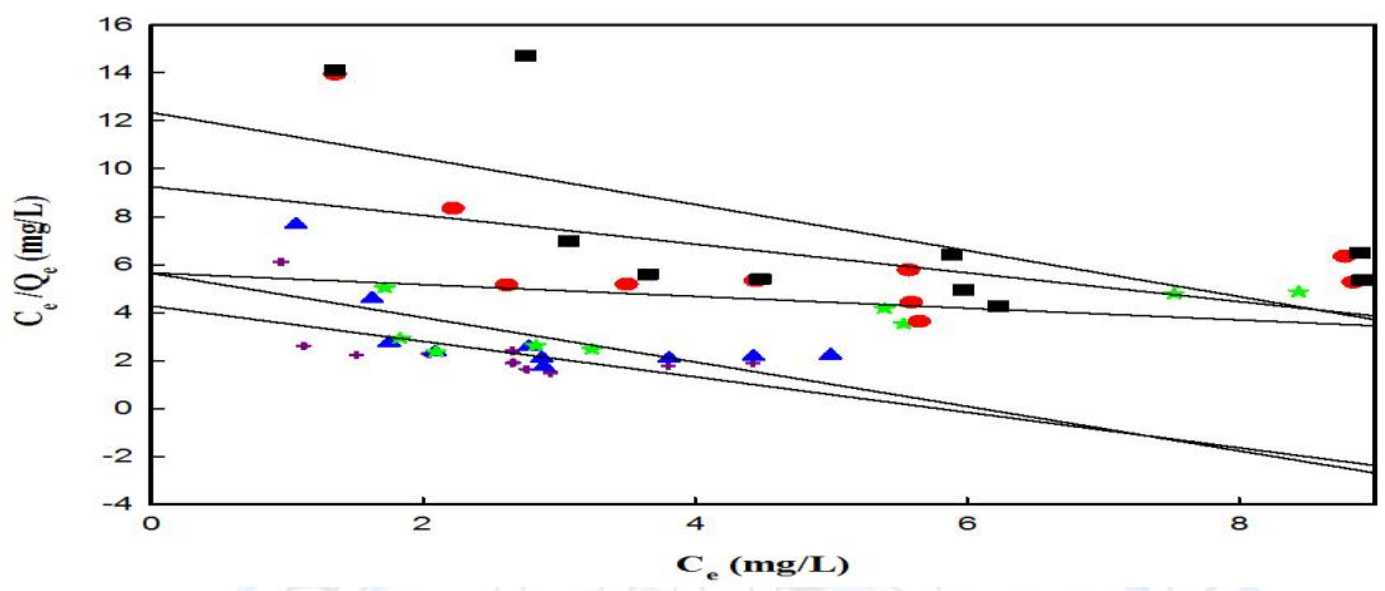

شكل (12) أيزوثيرم لانكماير لصبغة الأيوسين على سطح مخلفات دبس التمر.

وتم تحليل نتائج امتزاز صبغة الأيو سين على السطح مخلفات دبس التمر وفق أيزوثيرم فرندلخ(13) الخطية و التي هي: $\ln Q_{e}=\ln K_{F}+\frac{1}{n} \ln C_{e}$

ونتائج موضحة في شكل(13) لسطح مخلفات دبس التمر. ومتغير ات أيزوثيرم فرندلخ موضحة في جدول (4).

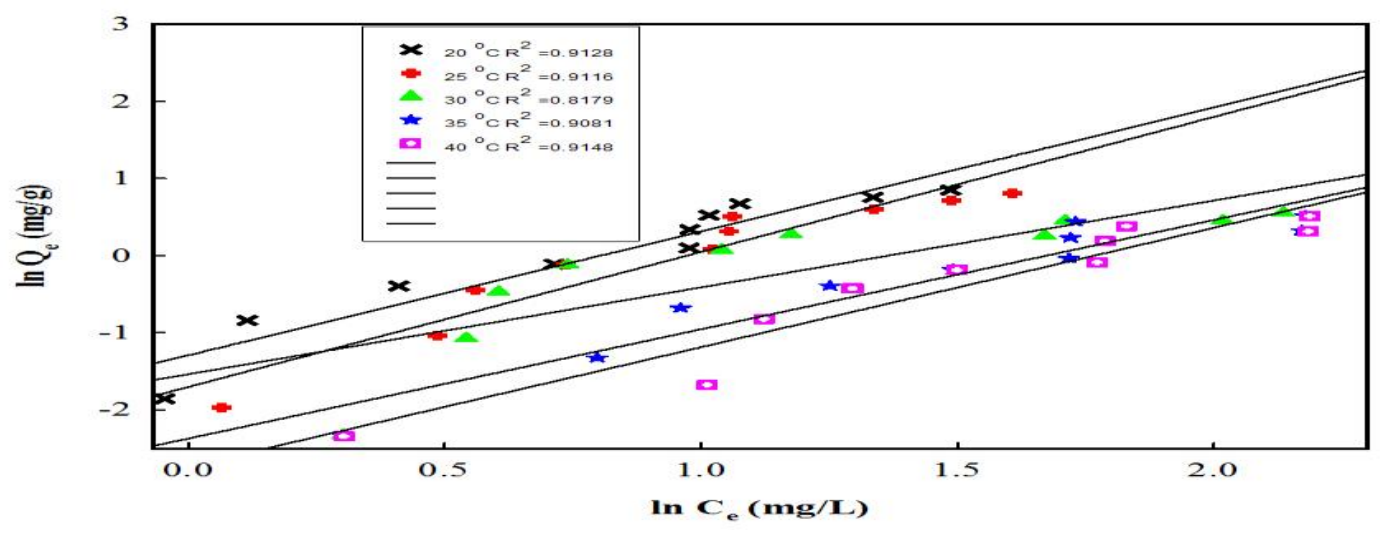

شكل (13) أيزوثيرم فرندلخ لصبغة الأيوسين على سطح مخلفات دبس التمر.

إنّ قيم معامل الارتباط (R²) و التي تكون بين مدى(0.818-0.915) إذ نلاحظ ملائمة معادلة فرندلخ لنتائج امتز از صبغة

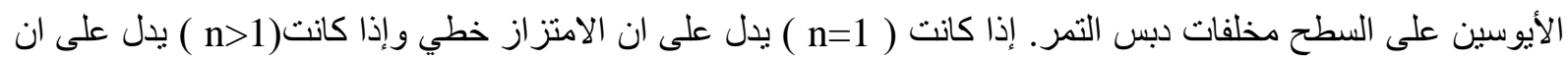


دراسة امتزاز صبغة الأيوسين على سطح مخلفات دبس التمر

عبد الرحمن خضير عبد الحسين الطائي مروة إسماعيل مبارك

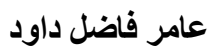

الامتز از فيزيائي و إذا كانت (n<1) يدل على ان الامتز از كيمائي، إذ إنّ فيمn نتر اوح بين (1.750-1.126) فنجد أنّها أكبر

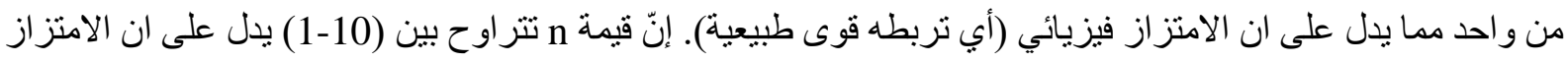
جيد. وتم تحليل النتائج وفق أيزوثيرم دوبنين الخطية والتي تعتبر أعم من لانكماير وفرندلخ على السطح الغير متجانس

ومعادلته الخطية هي: -

$\ln Q_{e}=\ln q_{\max }-\beta \varepsilon^{2}$

$\varepsilon=\operatorname{RT} \ln \left(1+\frac{1}{\mathrm{C}_{\mathrm{e}}}\right)$

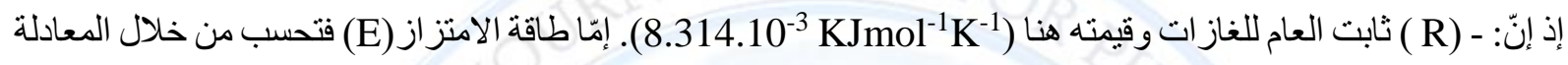

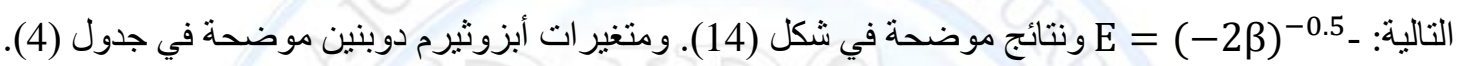

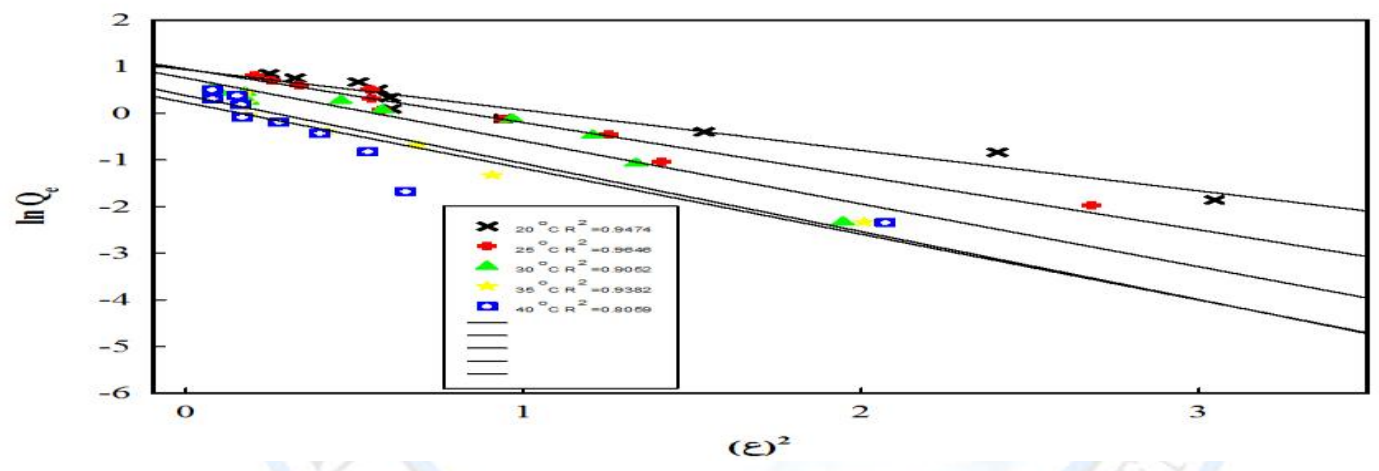

شكل (14) أيزوثيرم دوبنين لصبغة الأيوسين على سطح مخلقات دبس التمر.

إنّ معادلة الطاقة تعطينا تصور عن ميكانيكية الامتزاز، إذ إنّ E<8KJ/mol يدل على ان القوى الفيزيائية هي المؤثرة على الامتزاز وان E>16 يدل على انتشار الجزيئات و عندما تكون E بين (16-8) يدل على ان الامتزاز يوجه بو اسطة التبادل

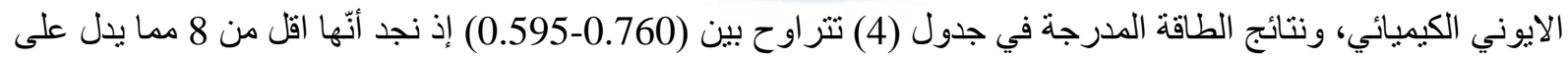
ان القوى هي فيزيائية أي الامتز از فيزيائي و هذه نفس النتيجة التي توصلنه لها من أيزوثيرم فرندلخ. كذلك نجد ان الطاقة تقل

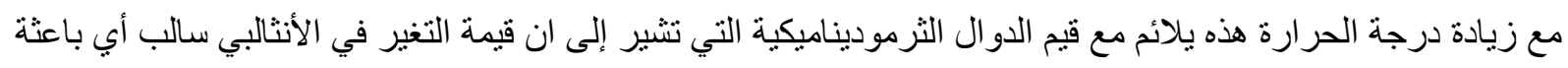

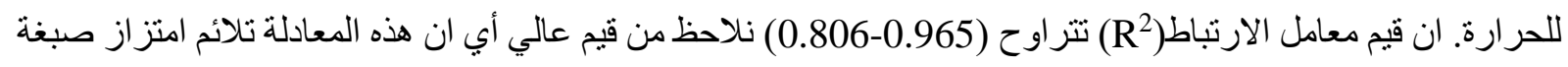

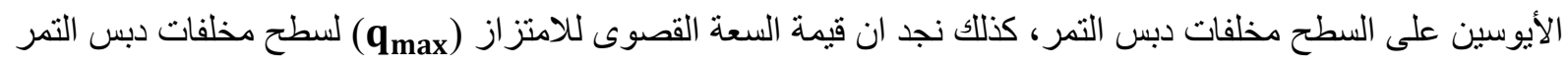
تقل مع زيادة درجة الحر ارة و هذه يتفق مع كمية المادة الممتزة التي تقل مع زيادة درجة الحرارة وقيمها تتر اوح بين (-1.256) 2.550. نم تحليل النتائج وفق أيزوثيرم تمكن كما في شكل (15) و المتغيرات مدرجة في جدول (4). 
دراسة امتزاز صبغة الأيوسين على سطح مخلفات دبس التمر

عبد الرحمن خضير عبد الحسين الطائي مروة إسماعيل مبارك

عامر فاضل داود

$Q_{e}=B \ln K_{T}+B \ln C_{e}$

من خلال قيم معامل الارتباط التي تتراوح بين (0.953-0.872) أنهّا تلائم امتز از صبغة الأيو سين على السطح مخلفات دبس

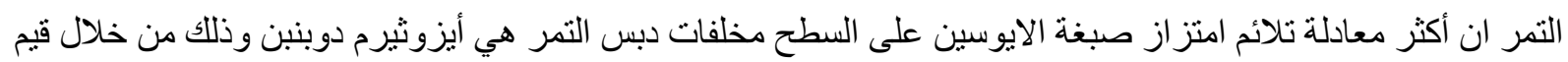

معامل الارتباط العالية لها.

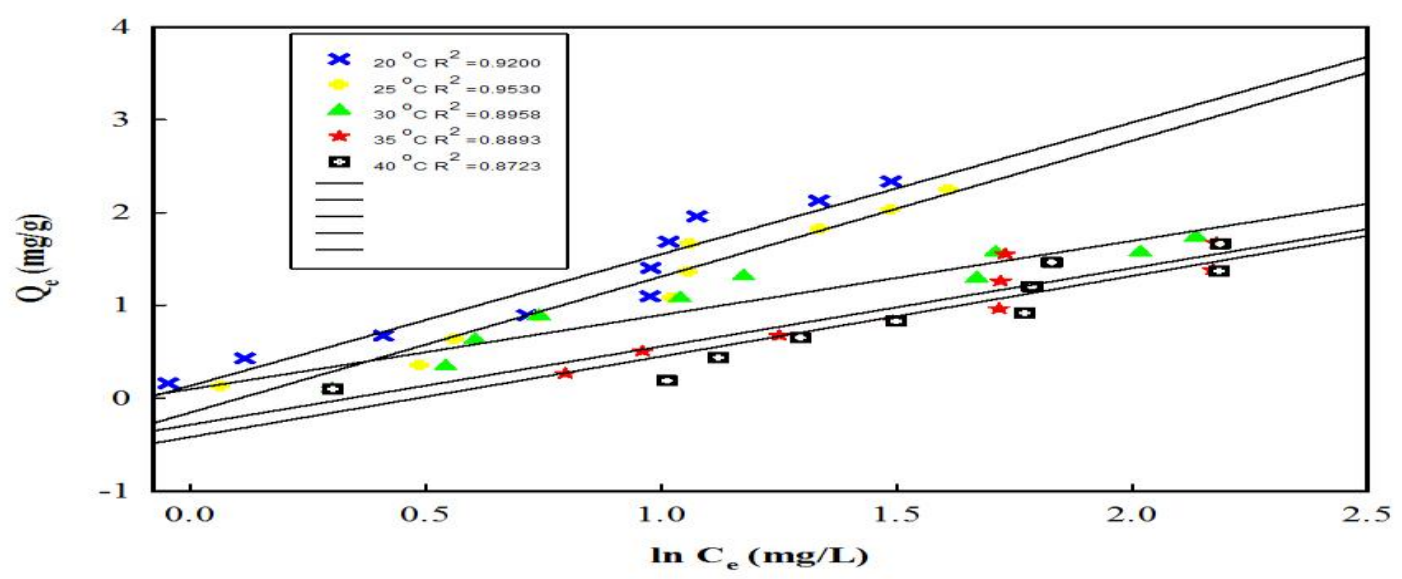

شكل(15) أيزوثيرم تمكن لصبغة الأيوسين على سطح مخلفات دبس التمر.

جدول (4) متغيرات ايزوثيرم فرندلخ ودوينين وتمكن لصبغة الأيوسين على سطح مخلفات دبس التمر.

\begin{tabular}{|c|c|c|c|c|c|c|c|c|c|c|}
\hline \multicolumn{4}{|c|}{ فرندلخ } & \multicolumn{4}{|c|}{ دوبنين } & \multicolumn{3}{|c|}{ تمكن } \\
\hline $\mathrm{T}^{\circ} \mathrm{C}$ & $K_{F}$ & $\mathrm{n}$ & $\mathrm{R}^{2}$ & $\boldsymbol{\beta}$ & $\mathbf{q}_{\max }$ & $\mathbf{E}$ & $\mathbf{R}^{2}$ & $K_{T}$ & B & $\mathbf{R}^{2}$ \\
\hline 20 & 0.274 & 1.606 & 0.913 & -0.000867 & 2.550 & 0.760 & 0.947 & 1.097 & 1.420 & 0.920 \\
\hline 25 & 0.182 & 1.750 & 0.912 & -0.00115 & 2.586 & 0.659 & 0.965 & 0.899 & 1.466 & 0.953 \\
\hline 30 & 0.215 & 1.126 & 0.818 & -0.001348 & 2.121 & 0.609 & 0.905 & 1.127 & 0.800 & 0.896 \\
\hline 35 & 0.093 & 1.416 & 0.908 & -0.00146 & 1.464 & 0.585 & 0.938 & 0.711 & 0.845 & 0.889 \\
\hline 40 & 0.065 & 1.548 & 0.915 & -0.001411 & 1.256 & 0.595 & 0.806 & 0.616 & 0.868 & 0.872 \\
\hline
\end{tabular}

\section{المصادر}

1. Nassar, N.N., Marei, N.N., Vitale, G. and Arar, L.A. (2015), "Adsorptive removal of dyes from synthetic and real textile wastewater using magnetic iron oxide nanoparticles: Thermodynamic and mechanistic insights". Canadian Journal of Chemical Engineering, 93 (11), pp: 1965-1974. 


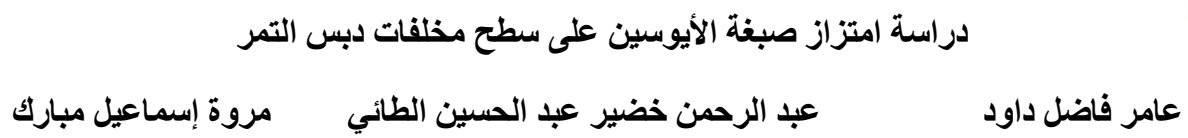

2. Tadesse, B., Teju, E. and Megersa, N. (2015), "The Teff straw: a novel low-cost adsorbent for quantitative removal of $\mathrm{Cr}(\mathrm{VI})$ from contaminated aqueous samples". Desalination and Water Treatment, 56(11), pp: 2925-2935.

3. Wang, Y., Tang, X.W. and Wang, H.Y. (2015), "Characteristics and mechanisms of Ni (II) removal from aqueous solution by Chinese loess". Journal of Central South University, 22 (11), pp: 4184-4192.

4. Mane, S., Ponrathnam, S. and Chavan, N. (2016), "Selective solid-phase extraction of metal for water decontamination". Journal of Applied Polymer Science, 133, p: 1.

5. Zhang, Z.F., Wang, W.B. and Wang, A.Q. (2015), "Highly effective removal of Methylene Blue using functionalized attapulgite via hydrothermal process". Journal of Environmental Sciences-China, 33, pp: 106-115.

6. Tavlieva, M.P., Genieva, S.D., Georgieva, V.G. and Vlaev, L.T. (2015), "Thermodynamics and kinetics of the removal of manganese (II) ions from aqueous solutions by white rice husk ash". Journal of Molecular Liquids, 211, pp: 938-947.

7. Sandeep Keshari Bhoi (2010), "Adsorption charecterstics of congo red dye on to PAC and GAC based on S/N ratio: ataguchi approach". A Project, ORISSA - 769 008, INDIA.

8. Randhawa, N.S., Dwivedi, D., Prajapati, S. and Jana, R.K. (2015), "Application of manganese nodules leaching residue for adsorption of nickel (II) ions from aqueous solution". International Journal of Environmental Science and Technology, 12 (3), pp: 857864.

9. Liu, M.X., Dong, F.Q., Kang, W., Sun, S.Y., Wei, H.F., Zhang, W., Nie, X.Q., Guo, Y.T., Huang, T. and Liu, Y.Y. (2014), "Biosorption of Strontium from Simulated Nuclear Wastewater by Scenedesmus spinosus under Culture Conditions: Adsorption and Bioaccumulation Processes and Models". International Journal of Environmental Research and Public Health, 11 (6), pp: 6099-6118.

10. Smaranda, C. 1, Gavrilescu, M .1 and Bulgariu, D. 2, (2010), "Studies on Sorption of Congo Red from Aqueous Solution onto Soil ". Al. I .Cuza, University of Iaşi Romania.

11. Jadhav,S. R. N. Varma, A. Sharma and P. K. Bhattachary (2001), "Flux and retention analysisduring micellar enhanced ultrafiltration for the removal of phenol and aniline". Sep. Purif. Technology 24, pp: 541-547. 


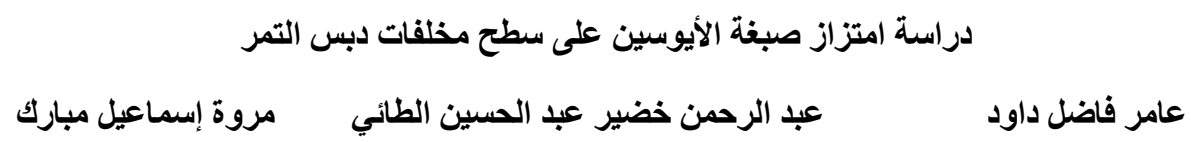

12. Haciyakupoglu, S., Orucoglu, E., Esen, A.N., Yusan, S. and Erenturk, S. (2015), "Kinetic modeling of selenium (IV) adsorption for remediation of contaminated aquatic systems based on meso-scale experiments". Desalination and Water Treatment, 56 (5), pp: 12081216.

13. Samuel, M.S., Abigail, E.A.M. and Chidambaram, R. (2015), "Isotherm Modelling, Kinetic Study and Optimization of Batch Parameters Using Response Surface Methodology for Effective Removal of Cr (VI) Using Fungal Biomass". Plos One, 10, p: 3. 